\section{Reactions by Consumers in a Farmers' Market to Prices for Seedless Watermelon and Ratings of Eating Quality}

\author{
Charles W. Marr ${ }^{1}$ and \\ Karen L.B. Gast ${ }^{2}$
}

Additional index words. Citrullus lunatus, triploid watermelon, consumer preference ratings

Summary. Consumers in six farmers' market locations in Kansas indicated that they would pay an additional $5 \varnothing$ per pound for seedless watermelons. When asked to rate seeded and seedless melons on a 1 to 10 scale after tasting samples, consumers rated the seedless melon 7.35 and the seeded melon 7.01. There were no practical differences among the six locations studied. With the difficulties in growing seedless melons and greater costs of production, growers and marketers need to assess carefully the market potential for seedless watermelons and plan a merchandising strategy to differentiate seedless from seeded melons. Our studies indicated a slight eating quality preference for seedless melons.

$\mathrm{S}$ eedless watermelons have become more popular in the past several years. Seedless cultivars are estimated currently at 5\% of the commercial watermelon market, with a potential share of $15 \%$ to $50 \%$ (Karst, 1990). Much of the seedless melon market may be driven by sales of cut melons for produce counters, salad bars, institutional servings, and similar outlets with an emphasis on merchandising (Unrein, 1990).

'Professor.
${ }^{2}$ Aosistant Professor.
Department of Horticulture, Kansas State University,
Manhattan, KS 66506. Contribution no. 90-139T from
the Kansas Agricultural Experiment Station.
the Kansas Agricultural Experiment Station.
Seedless watermelons require warm temperatures for germination, may have more defects in early melons, and have higher seed costs (Motes et al., 1988). Seeds of standard watermelons cost about $\$ 3 / 1000$ seeds. Newer hybrid cultivars cost about $\$ 18$ to $\$ 20 / 1000$ seeds. However, seedless watermelon seeds may cost from $\$ 150$ to $\$ 200 / 1000$ seeds, and planting seed in the same manner and quantities that standard melons are planted could result in seed costs of $\$ 700$ to $\$ 900 /$ acre. Seedless melons usually are transplanted from greenhouse-grown plants, and intensive production practices such as plastic mulches and rowcovers, are often used to create the warmer growing conditions required. Thus, seedless melons cost more to produce and there is greater risk in production. Traditional melon growers are often reluctant to plant seedless melons because they are

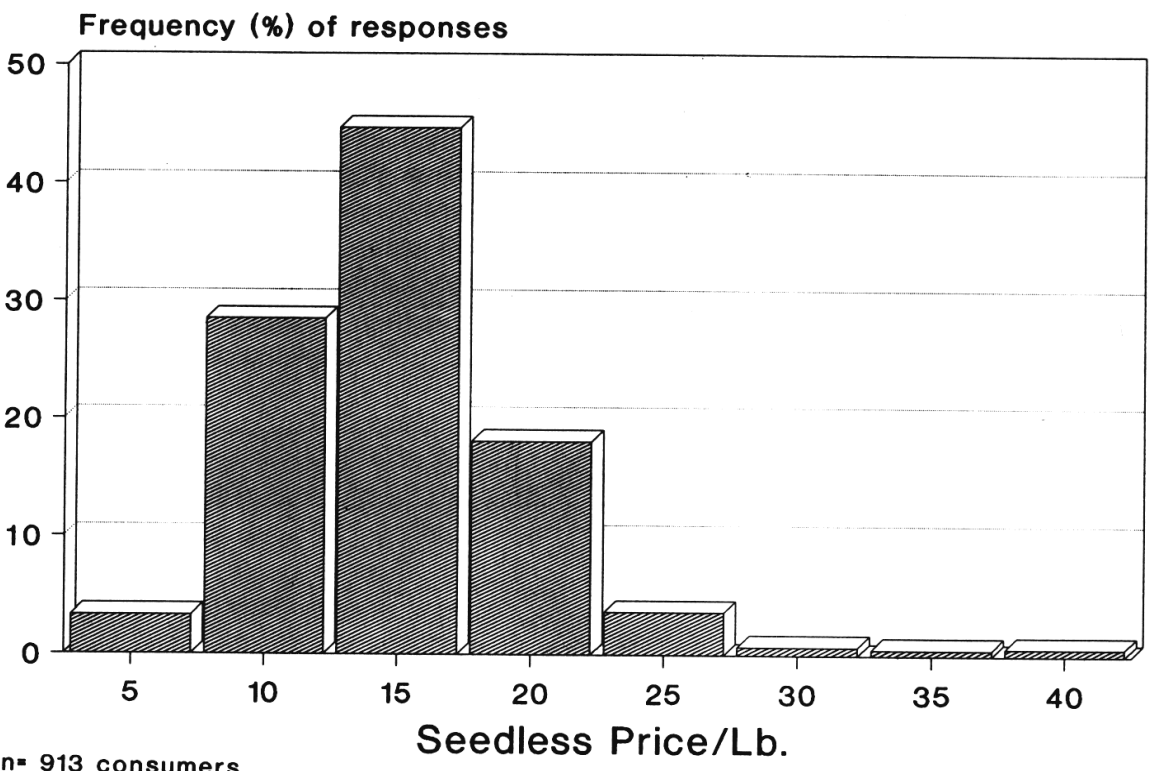

Fig. 1.Price that consumers would pay for seedless watermelon in six Kansas farmers markets based on seeded melon prices at $10 \phi \lambda 6 . n=913$ consumers.

Table 1. Consumer mutings of prices for seedless vs. seeded watermelons and preference for eating quality of seedless and seeded watermelons in six Kansas furmers markets.

\begin{tabular}{|c|c|c|c|}
\hline Variable & No. (n) & Mean value & SD \\
\hline \multicolumn{4}{|l|}{ Seedless price compared to } \\
\hline $10 \$ / 1 \mathrm{~b}$ for seeded melon & 901 & 14.90 & 5.19 \\
\hline & & \multicolumn{2}{|c|}{ Rating } \\
\hline \multicolumn{4}{|l|}{ Preference rating } \\
\hline Seedless King of Hearts & 885 & 7.35 & 1.81 \\
\hline Seeded Mirage & 894 & 7.01 & 1.76 \\
\hline
\end{tabular}

unsure of the potential returns that seedless melons may produce. Melon marketers have had difficulties in estimating how to price seedless melons and in selling seedless along with seeded melons.

In Aug. 1990, consumer preference studies were conducted in six farmers' market locations in Kansas to determine how much more consumers were willing to pay for seedless melons and to obtain a general reaction to flavor and quality of seedless melons. Ratings were done on Saturday, 4. Aug. 1990, or the nearest possible market session. Cultivars used were 'King of Hearts' seedless comLocations were suburban markets in Kansas City (Overland Park) and Wichita, university town markets in Manhattan and Lawrence, a downtown market in Wichita, and a market in the agricultural community of pared to 'Mirage' seeded melons. 
Hutchinson. Melons used in the test were grown in the same plot, with 'Mirage' used as the pollinizer for the triploid melon. 'Mirage' and 'King of Hearts' were chosen as typical melon cultivars that are widely available, currently being grown in commercial production, and have shown strong consumer acceptance for eating quality. All melons were harvested on the same day. Master gardener volunteers assisted in explaining the rating process to consumers, as well as preparing samples and collecting data. There were 913 people surveyed in the six locations. Consumers were first shown cut halves of each melon and were asked, "If the seeded melon were priced at $10 \varnothing$ per pound, how much would you be willing to pay for the seedless melon?" Price for the seeded melon was determined from a typical, mid-summer price for watermelons offered for sale in farmers' markets. Consumers responded on a rating card with prices from $5 \varnothing$ to $40 \varnothing$ at $5 \varnothing$ increments. Consumers were then given samples of each melon and asked to rate each on a 1 to 10 scale, with a rating of 5 being "average acceptability."

As seen in Table 1, consumers were willing to pay $\approx 5 \phi / \mathrm{lb}$, or $50 \%$ more for the seedless melon. Acceptability of each melon was similar, with mean ratings of 7.01 and 7.35 for the seeded and seedless melons, respec- tively. Although no demographic characteristics were taken, consumer comments indicated that seedless melons seemed to be received better by younger consumers-especially mothers with small children. Older consumers seemed to prefer traditional watermelons. The frequency of the price responses, as seen in Fig. 1, shows a peak response at the mean and a strong reluctance to pay more than twice the seeded melon price for a seedless one. However, similar preference ratings, as seen in Fig. 2, would indicate that consumers might pay a greater price because seedless melons were rated to be of equal or greater quality.

It may be debatable whether $15 \phi /$ lb compared to $10 \propto / \mathrm{lb}$ is a "considerable" price increase. Considering the cost of seedless melon seed, production difficulties, and increased risk, it is our opinion that a substantial premium price must be received for the product. Melon producers should determine carefully costs of production and break-evenprices when considering production of seedless melons. Ifproducers determine that their break-even cost of production/ marketing is higher than the $50 \%$ price "premium" that consumers indicated that they would spend, the an aggressive merchandising strategy is essential to get consumers to differentiate between the two melon types and accept seedless watermelons as meriting a higher price based on the quality of the product. Our studies confirm that consumers were willing to pay more based on appearance alone, and eating quality tests indicated that consumers would not be disappointed by the eating quality and that consumers perceive a "desired benefit" from the seedless product.

\section{Literature Cited}

Karst, T. 1990. Seedless watermelon sure to grow. The Grower 23(8):61.

Motes, J., J. Criswell, D. McCraw, G. Barnes, R. Schatzer, D. Tilley, S. Fargo, and G. Cuperus. 1988. Cucurbit production and pest management. Oklahoma Ext. Circ. E853.

Unrein, J. 1990. When merchandising seedless, seeing is believing-and buying. The Packer. 5 May 1990.

\section{Acknowledgements}

We express our appreciation to Master Gardener volunteers in Johnson, Sedgwick, Douglas, and Riley counties and to county agents in the six market locations for their assistance in conducting these studies.

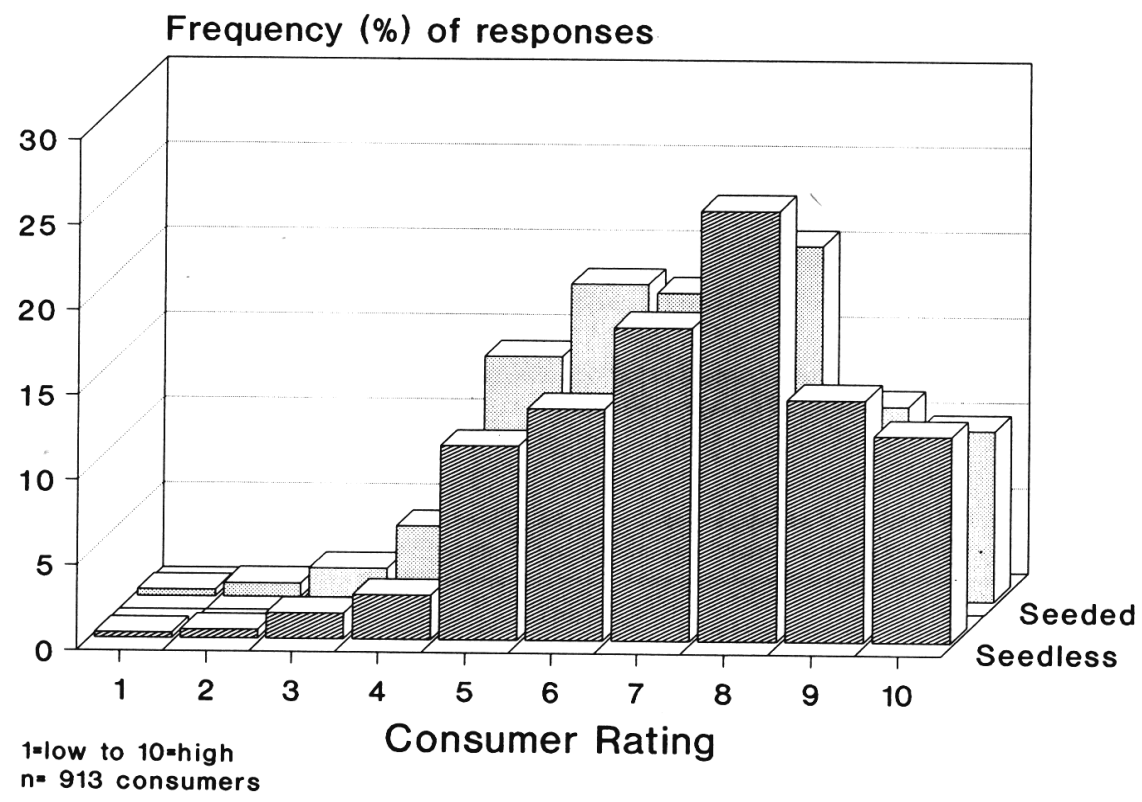

Fig. 2. Consumer ratings for seedless 'King of Hearts' and seeded 'Mirage' watermelons in six Kansas farmers' markets based on flavor and eating quality. $I=1020$ to $10=b i g h ; n=913$ consesmors. 